Article

\title{
Exploring the Strategic Intent and Practices of University Accelerators: A Case of Australia
}

\author{
Alex Maritz ${ }^{1, * \mathbb{C}}$, Quan Nguyen ${ }^{1}(\mathbb{C})$ and Hsin-Ming Hsieh ${ }^{2}$ \\ 1 La Trobe Business School, La Trobe University, Melbourne, VIC 3086, Australia; quan.nguyen@latrobe.edu.au \\ 2 International Association of Organizational Innovation, Hobe Sound, FL 33455, USA; minnie@iaoiusa.org \\ * Correspondence: a.maritz@latrobe.edu.au
}

Citation: Maritz, A.; Nguyen, Q.; Hsieh, H.-M. Exploring the Strategic Intent and Practices of University Accelerators: A Case of Australia. Sustainability 2021, 13, 10769. https:/ / doi.org/10.3390/su131910769

Academic Editors: Mário José Baptista Franco, Margarida Maria Mendes Rodrigues and Rui Jorge Rodrigues da Silva

Received: 27 August 2021

Accepted: 24 September 2021

Published: 28 September 2021

Publisher's Note: MDPI stays neutral with regard to jurisdictional claims in published maps and institutional affiliations.

Copyright: (C) 2021 by the authors. Licensee MDPI, Basel, Switzerland. This article is an open access article distributed under the terms and conditions of the Creative Commons Attribution (CC BY) license (https:/ / creativecommons.org/licenses/by/ $4.0 /)$.

\begin{abstract}
University accelerators are a recent but rapidly growing phenomenon that not only enhance regional entrepreneurial ecosystems but influence the success of university startups and regional development and prosperity. The aim of this research is to explore the alignment of university strategic intent and practices with the impact and outcomes of university startup accelerators. The research design includes emergent enquiry perspectives aligned to inductive and nascent exploratory research. This is the first global algorithmic study using Leximancer techniques to examine the integration of university intent and accelerator impact using institutional theory as a foundation. Neoteric reviews provide conflicting points of view regarding university accelerators as startup launchpads or vehicles for entrepreneurial learning, and the findings suggest a disparity between university accelerators and university strategic intent, primarily a result of the incongruent interplay of substantive and symbolic management practices. The findings provide not only critical grounding and insights for researchers, practitioners, and university leaders in their quest to engage with successful nascent entrepreneurs and university startups but, also, practical implications to align the strategic intent.
\end{abstract}

Keywords: university accelerators; strategic intent; accelerators; startups; sustainability; entrepreneurial ecosystems

\section{Introduction}

University accelerators (UA) are a recent but rapidly growing phenomenon, and over the past decade, universities have invested heavily in startup accelerator programs $[1,2]$. These accelerators not only enhance the local entrepreneurial ecosystems in which they operate but significantly influence the competitiveness and influence of startups in regional development, employment, and prosperity [3]. Despite their rapid proliferation, this new organizational form is still emergent; yet, the findings of these studies have varied substantially, highlighting both positive and negative impacts on startups [4]. UAs are university space and ownership-specific limited-duration programs lasting roughly three to six months that help cohorts of university ecosystem-associated startup ventures with their entrepreneurial process and aspirations, providing access to resources, knowledge, and important networks $[1,4,5]$.

Accelerators emerged in the private sector around 2005, with universities subsequently investing significantly in their own accelerators in the last decade. The rapid proliferation of UAs has resulted in universities adopting new models for commercialization and innovation, together with the emergence and development of the entrepreneurial university [6,7]. Positive impacts of accelerators include startups having higher survival rates than other new businesses not using accelerators [8,9]; yet, negative impacts are associated with accelerators not necessarily combining economic goals with social and ecological purpose; hence, there is a lack in respect of sustainable entrepreneurship and sustainabilityoriented startups $[10,11]$. Since accelerators can be viewed not only through their impact on individual startups but also as a catalyst for wider ecosystem development, such as 
entrepreneurship education and training, we are mindful of the heterogeneity of the context regarding disparate elements on impacts and outcomes [4,8,9,12]. UAs are specifically designed to better support the entrepreneurial efforts of students by providing targeted entrepreneurship education as a cohort-based initiative within specified entrepreneurial spaces, providing a startup infrastructure for entrepreneurial clusters and providing authentic training experiences for nascent entrepreneurs $[2,13,14]$. It thus stands to reason that UA operations and impacts need to closely align with the strategic intent of their sponsor, the applicable university in this case in point [4]. Such a strategic intent may resemble the entrepreneurial university, for example, or specific research, teaching, and engagement impacts that include social inclusion and sustainability, often referred to as the substantive impact. On the other hand, many universities, whilst strategically intending to provide meaningful impact, do not achieve the desired effects due to a myriad of reasons; in such cases, this may be the result of symbolic inferences [13]. We do acknowledge other entrepreneurial initiatives such as incubators and science parks, but this is outside the ambit of this study.

Embedding the integration and sustainability of UAs and university strategic intents and practices suggests two main patterns. First, neoteric accelerator reviews provide conflicting and disparate points of view regarding the impacts and outcomes of UAs, such as disparity regarding entrepreneurship education imperatives and misalignment of entrepreneurial/startup initiatives and university strategic intent $[15,16]$. Second, neoteric accelerator reviews provide a lack of evidence regarding studies on the interface between UAs and the strategic intent of universities, highlighting significant incongruences between substantive and symbolic outcomes $[17,18]$. These two related research gaps form the rationale of this paper. Our aim is to demystify the disparate scholarship points of view regarding the outcomes and impact of UAs, particularly regarding the alignment of university strategic intent and practices. We believe our main contribution to the UA body of knowledge is the first global algorithmic study to align university strategic intent with UA impact within the context of Australian universities. This paper argues that, although UAs have grown rapidly in Australian universities, much still needs to be done to enhance the substantive and symbolic actions to further develop sustainable UAs. We chose Australian UAs as this study in an extension of Maritz et al.'s work [12]. The findings provide critical grounding and insights for researchers, practitioners, and university leaders globally to closely align UAs with the strategic intent of their universities.

Overall, given the nascent state of the research on university startup accelerators and university entrepreneurial strategy and intent, the goal of this exploratory research is to construct an understanding of, as opposed to verifying, a phenomenon. We aim to offer an understanding of the heterogeneous elements of UAs and set forth the foundations for a research agenda for scholars in this field of research.

We commence our study with a review of the prominent and neoteric global UA literature, followed by algorithms that generate thematic clustering based on keyword co-occurrences to explore the interface between university strategic intent and university accelerator impact. In the discussion, we provide outcomes against the background of our two main patterns identified above. This paper concludes with implications and suggestions for the sustainable development of UAs and directions for future research in this emerging landscape.

\section{University Accelerators}

Policymakers have long-viewed universities as significant contributors to entrepreneurship, startup activities, commercialization of innovation, job creation, and economic growth [2,5]. UAs form an integral component of such contributions, further enhancing the entrepreneurial ecosystems [19] in which they operate and, more specifically, the entrepreneurship education ecosystem [20], the entrepreneurial university [21], and entrepreneurship education [12]. Prior to examining the value and impact of UAs, it is 
important to conceptualize the alignment of these ecosystems within the value creation component of the entrepreneurship impact within universities [22].

Entrepreneurial ecosystems have become very prominent over the last decade, and the current thinking can be seen as a result of developments in several related literatures and practices, such as context, high-growth entrepreneurship, clusters, regional innovation systems, entrepreneurial environments, business ecosystems, and institutions [19]. Whilst universities align with much of this literature and practice, they particularly align with an institutional perspective in that they play a significant institutional role in reducing unproductive entrepreneurship to productive and high-growth entrepreneurship [23]. Entrepreneurial ecosystems are combinations of social, political, economic, and cultural elements within a region that support the development and growth of innovative startups and encourage nascent entrepreneurs and other actors to take the risk of starting, funding, and otherwise assisting high-risk ventures [24]. Entrepreneurial ecosystems are said to be heterogeneous in the system-level characteristic of resilience, enabling a capacity to absorb disturbances and undergo the changes necessary to transform its essential behaviors, structures, and identity into a system that is better able to respond to disruptions, such has been found in the COVID-19 pandemic [25]. Despite the functional characteristics and dynamics [26] of entrepreneurial ecosystems, there is a scarcity of credible, accurate, and comparable metrics to measure the impact and outcomes of this phenomenon $[27,28]$. This research goes a long way towards addressing this gap.

The entrepreneurial university has evolved as a result of the gradual shift from managerial economies to entrepreneurial economies, with entrepreneurship considered a key driver of economic development $[7,27]$. Being argued as a "catalyst for the development of entrepreneurial ecosystems", universities have increasingly been making a greater contribution and significant impact on socioeconomic development [29]. Consequently, their traditional roles and missions have been further expanded, from teaching and researching, to also include entrepreneurship [23]. Embarking on the entrepreneurial paradigm, from purely an academic entity, an entrepreneurial university "actively seeks to innovate in how it goes about its business" to create "a substantial shift in organizational character" to become a "stand-up" institution essentially via embracing knowledge transformation, university-industry collaboration, and creating a unique space for enabling entrepreneurial opportunities [30]. The transformation into entrepreneurial universities requires "an irreducible minimum" with five elements, including a strengthened steering core, an expanded developmental periphery, a diversified funding base, a stimulated academic heartland, and an integrated entrepreneurial culture. During this transformation process, entrepreneurial universities are argued to actively interact and collaborate with the government and industry in a triple-helix model to facilitate the innovations [21]. More recently, a university per se can even be viewed as an "entrepreneurial ecosystem hub" or develop its own entrepreneurial university ecosystem [7] besides traditional education activities [12]. The quest for a university to become entrepreneurial has associations with dynamic symbolic and substantive inferences [15,17], notwithstanding a startup mindset [2,4]. This research also examines this gap.

Entrepreneurship education (EE) and the entrepreneurship education ecosystem (EEE) $[12,20]$ form an integral component of entrepreneurship ecosystems and most often associate or link universities with regional ecosystems [24,26]. The main stakeholders include governments, the industry, universities, and nascent entrepreneurs. EEE is an extension of the entrepreneurial ecosystem and the entrepreneurial university, with EE at the heart of these ecosystems. Five approaches taken together contribute to the formation of far-reaching EEE, vis, expanding the footprint of EE across the university, action or experiential learning, and scientist engagement in entrepreneurial modules, practice theory-based capability development, providing the infrastructure with the entrepreneurial community and policymakers and providing facilities for networking with students and alumni [20]. We define entrepreneurship education within the context of university accelerators, such as contextualized content, experiential methods, and initiatives supporting the creation of en- 
trepreneurial knowledge, competencies, and experiences within entrepreneurial spaces that enable diverse participants to initiate and participate in entrepreneurial values, creating processes such as transformation, disruption, and startups. Despite the significant growth of the Australian EEE ecosystem in the past decade, there is a sparse and inconsistent distribution of EE programs and initiatives across Australian universities [12,15]. This research further explores the gap between the EE impact and university strategic intent within the context of UAs.

University startup accelerators emerged about a decade ago, after the successful introduction of private sector accelerators close to two decades ago $[1,6]$. UAs also emerged as a result of the growth in regional entrepreneurial ecosystems, rise of the entrepreneurial university, advances in entrepreneurship education, and entrepreneurial education ecosystems. This was further enhanced by the need of university commercialization of innovation, open innovation, and driven by the changing economics of early stage university associated startups, especially those in digitalization and technology, which benefit from a dramatic decrease in the costs of experimentation and validation [31]. Within this context, UAs provide time-limited and intense mentorship and entrepreneurship education and training, allowing nascent entrepreneurs to focus their attention on their proposed startup, thus leading to quicker growth or quicker failure - which can be beneficial in pivoting to highervalue opportunities and impacts. Successful UAs have demonstrated they have a key role to play in boosting regional startup ecosystems and providing a network foundation for entrepreneurial engagement between founders, investors, and other university stakeholders $[5,10,11]$. Cohen et al. (2017) defined accelerators as a fixed term, cohort-based program for startups, including mentorship and/or educational components, that culminate in a graduation event [4]. Hence, this differentiates accelerators from other types of programmatic interventions whose core role is to serve as intermediaries between startups and a complex landscape of resources. This further highlights the heterogenous design elements of accelerator programs, in that all accelerators are unique in context, delivery, outcomes, and more importantly, intent and impact [2].

Just what constitutes the optimal design and process of successful UAs is an ongoing and emergent discussion $[4,6,10,11,13,31]$; hence, we provide an overview of the services associated with UAs, with contextual examples in parentheses: entrepreneurship education and training (value proposition, business model, lean startup, analytical tools and design thinking); mentorship; coworking space (laboratory and office space); tax and legal advice; startup networking (startup community events and regional entrepreneurial ecosystems); investor networking (VC, angels and funders); technology partner networking; international partner networking (global entrepreneurial ecosystems and supply chains and internationalization) and commercialization of innovation (intellectual property), to name but a few. Many studies have amplified UAs as entrepreneurship education $[1,4,5]$, yet others regard UAs as vehicles for university startups [12,14,20]. Our opinion is that UAs require an all-inclusive approach to integration, yet aligned to the strategic intent and practices of the university ecosystem in which they operate. UAs are all-encompassing, including startup infrastructures for entrepreneurial clusters [13], authentic training experiences for nascent entrepreneurs [14], student startup facilitation and growth [2], entrepreneurial learning [1], innovation acceleration [6], developing sustainable business models [11], absorptive capacity and growth [32], process and impact [10], open innovation [24], and association with EEE and EE [12].

From a sustainability perspective, UAs have the ability to create not only economic outcomes but, also, positive social and/or environmental impacts, thereby supporting ventures combining economic goals with social and ecological purposes. This is further enhanced by the notion that startups who have been supported through accelerators have higher survival rates than other new businesses [10]. UAs also have expertise and impact in developing sustainable business models, highlighting societal prevalence and triple bottom line imperatives [11], and even aligning entrepreneurship education programs with capstone educational opportunities [1]. There is, however, much dialogue 
and variations as to whether UAs are startup launchpads or vehicles for entrepreneurial learning $[1,2,5,12,15,26]$. Findings of the UA literature, whilst still emergent, vary substantially. This research examines such variations with regard to university strategic intent and practices.

Within the context of the literature above, this research aims to explore the strategic intent of university accelerators. We refer to university strategic intent as a high-level commitment of the means by which universities will achieve their vision; it is a means of creating a desirable outcome or future (stated in present terms). It implies the purpose that universities endeavor to achieve. With specific references to our entrepreneurship (ecosystem) context, we examine such university strategic intent with regard to UAs and entrepreneurial startup activity [16]. We further explore substantive and symbolic environmental strategies to provide inference to the impact of such strategic intent $[17,18]$. We regard substantive inference as the action to meet certain expectations that often require changes in core practices, long-term commitments, and investments in corporate culture, with word associations such as proactive, loyalty, and commitment. Symbolic inference refers to expressive human action, the rhetorical mobilization of symbols to act in the world, with word associations such as a desire to appear, not necessarily reflecting a commitment. Substantive and symbolic strategies within this context usually align with the institutional theory, henceforth adopted as a theoretical underpinning in this research $[17,18]$. This provides a springboard for our Leximancer research design and methods, further discussed in the section to follow.

\section{Research Methodology}

Our research design included a review of prominent and neoteric global scholarship on university accelerators, inclusive of closely aligned entrepreneurial ecosystems, the entrepreneurial university, entrepreneurship education ecosystems, and entrepreneurship education. This enabled emergent enquiry perspectives aligned to inductive and nascent research [33], particularly regarding the emergent nature of university accelerator research [29]. We further entrenched our methodological approach based on the foundations of symbolic and substantive management theory $[17,18]$. From UA perspectives, substantive actions may produce tangible and objectively measured results like a significant alignment to university intent, and from symbolic perspectives, intangible and subjective results may influence shared meaning, perceived impact, beliefs, and stakeholder commitments. Since we do not offer final and conclusive solutions to this UA body of knowledge; rather, laying the foundation for further research, we deem this research as exploratory. Consequently, the research question we attempted to address in this paper was "What are the primary objectives and strategic intents expressed by the UAs?".

Data sourced for this research includes information publicly available in the investigated UA's websites, specifying the strategic intents (encompassing, for example, vision, mission, and objectives); the offerings; and activities of the investigated UAs. We collected the data from all 42 Australian universities across all states over the period 2-21 August 2021. With significance to a previous entrepreneurship education program study in Australia [12], we noted that not all universities offer entrepreneurship programs and that there is significant disparity between those that do. We found this to be the case with UA too; for example, only a few have four or more UAs, with most identified as hosting two UAs; six universities had no UAs. During this process, the collected data was manually screened by the authors for relevance. Other irrelevant information, for example, detailed activities, dates, and staff, was excluded from the inputs. A total of approximately 210 pages of documents from 93 university accelerators and incubators across Australia were finally collated for the analyses. The corpus, as described earlier, only included information that was directly related to the primary objectives and intentions of the examined UAs.

The institutional theory [34], which essentially focuses on how being compliant with the norms and rules embraced in an institutional environment reinforces the positions and legitimacy of its members [35], serves as the theoretical foundation for our research. 
Quantitative content analysis was adopted as the research method in this paper. The Leximancer software package was used to analyze the strategic intents and offerings of the investigated Australian UAs. Leximancer performs an automated content analysis, essentially in a language-independent manner [36], using complicated and empirically validated algorithms to examine the text, extract cooccurring information, and generate concept maps [37,38], which are based on the emergent cooccurrence matrix and connectedness of the concepts in the semantic network. The concept maps consist of major themes, and each theme includes a set of key concepts that are closely related and interconnected. The resulting quantitative analyses of textual corpus and concept maps offer a high level of face validity, stability, and reproducibility [37]. This software package has gained increasing popularity among researchers in various domains, including entrepreneurship [39], over the past two decades.

In the next section, we provide an overview of our results from our research design.

\section{Results and Discussion}

We explored the two main patterns of embedding the integration and sustainability of UAs and university strategic intent and practices from our research gaps, which form the rational of our paper. We did so on two fronts: firstly, a review of the neoteric literature on UAs, and, secondly, an examination using Leximancer of the UA alignment with strategic intents at Australian universities. From a literature perspective, we identified conflicting and disparate points of view regarding the impact and outcomes of UAs, particularly aligned to the UAs as startup launchpads or vehicles of entrepreneurial learning. The literature revealed a significant incongruence regarding the role of entrepreneurship education and entrepreneurial learning in UAs. The multiple roles and outcomes of the UAs were widespread across the literature, providing a foundation for our Leximancer analysis.

A set of themes emerged from Leximancer analyses, among which "program", "access", "community", "students", and "innovation" served as the cornerstones of the generated concept maps (see Figure 1). The detailed connectivity scores for the major themes reported by Leximancer are presented in Table 1.

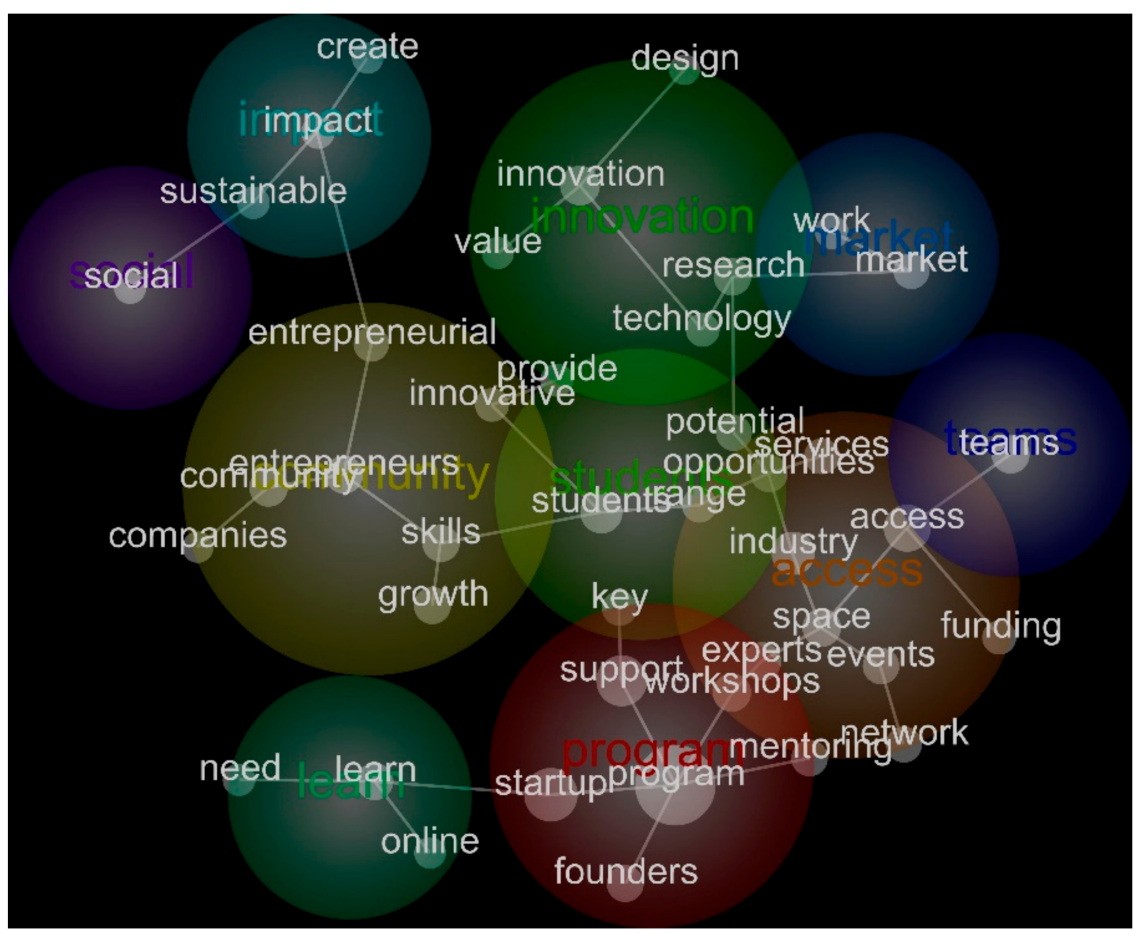

Figure 1. Concept map for the UA strategic intents and practices generated by Leximancer. 
Table 1. Major themes (and connectivity scores) emerged from the UA strategic intent corpus ${ }^{1}$.

\begin{tabular}{cc}
\hline Themes & Connectivity \\
\hline program & $100 \%$ \\
access & $53 \%$ \\
community & $43 \%$ \\
innovation & $25 \%$ \\
students & $16 \%$ \\
teams & $15 \%$ \\
learn & $13 \%$ \\
market & $11 \%$ \\
impact & $9 \%$ \\
social & $8 \%$ \\
\hline
\end{tabular}

${ }^{1}$ Connectivity scores were calculated by the authors based on the Leximancer outputs.

The "program", as the most important theme, consisted of major concepts that were largely related to different types of offerings and support directed to startups and their founders, including training workshops and mentoring services. The core concept of the program had the strongest connection to different types of workshops, run by experts, to develop a range of skills to support the founders. The second-most influential theme, "access", largely related to the opportunities to connect to industry experts, networking events, working space, and funding, as well as other supporting services. This was followed by the "community" theme, which reflected the context in which entrepreneurs can create an impact, participate in various events to seek growth opportunities and improve skills, and leverage innovative solutions. It was also notable that the "community" theme was relatively closely located to the "social" and "impact" themes, suggesting the desired (sustainable) impact expected to be created in society.

The theme "students" was located in the center, with a close proximity to and surrounded by the three above-mentioned themes, and the "innovation" theme, reflecting the close relationships between "students" and those major thematic domains. This theme essentially depicted how students' potential could be unlocked via a range of access to support services and technologies and opportunities provided to connect with industry partners. "Innovation" ranked fourth as a major theme and was placed closely to the "students", "market", and "community" themes, signaling the context in which innovations can be leveraged. "Innovations" were mostly mentioned in relation to research and technology, aiming to bring more value to the marketplace. Finally, it is noticeable that "learn" was only ranked seventh among the key themes, with a significantly lower number of hits and connectivity. This theme mostly addressed the essential learning techniques and skills necessary for the founders, particularly in the early stage, to unveil the market and customer needs. The major word-like concepts, their counts and relevance reported by Leximancer, are presented in Table 2.

Table 2. Major word-like concepts, counts, and relevance reported by Leximancer.

\begin{tabular}{ccc}
\hline Concepts & Count & Relevance \\
\hline program & 462 & $100 \%$ \\
startup & 211 & $46 \%$ \\
support & 173 & $37 \%$ \\
access & 126 & $27 \%$ \\
innovation & 101 & $22 \%$ \\
industry & 100 & $22 \%$ \\
students & 100 & $22 \%$ \\
community & 100 & $22 \%$ \\
teams & 94 & $20 \%$ \\
learn & 85 & $18 \%$ \\
entrepreneurs & 84 & $18 \%$ \\
\hline
\end{tabular}


Table 2. Cont.

\begin{tabular}{ccc}
\hline Concepts & Count & Relevance \\
\hline growth & 76 & $16 \%$ \\
founders & 76 & $16 \%$ \\
research & 70 & $15 \%$ \\
market & 70 & $15 \%$ \\
skills & 69 & $15 \%$ \\
entrepreneurial & 69 & $15 \%$ \\
workshops & 67 & $15 \%$ \\
space & 65 & $14 \%$ \\
experts & 64 & $14 \%$ \\
events & 63 & $14 \%$ \\
network & 63 & $14 \%$ \\
opportunities & 61 & $13 \%$ \\
mentoring & 60 & $13 \%$ \\
potential & 59 & $13 \%$ \\
impact & 56 & $13 \%$ \\
services & 53 & $12 \%$ \\
\hline
\end{tabular}

The results from the Leximancer analyses trigger some interesting observations and interpretations, which also facilitate practical implications. Firstly, with "program" and "access" emerging as the two most important areas, which received the most attention from UAs, the findings are moderately consistent with the earlier research, which delineated that the UAs' main functions include the provision of training experiences for entrepreneurs in the early stage [14] and the infrastructure for entrepreneurial clusters [13]. However, the investigated UAs did not place sufficient focus on the other key domains, such as accelerating innovations [6], crafting sustainable business models [11], or developing an absorptive capacity and facilitating growth [32], as suggested in the literature [40]. Secondly, the findings also moderately corroborated earlier research when having "community" as an important theme but only being ranked third in the list, suggesting some (but it might not be enough) efforts made by UAs to integrate with entrepreneurial education ecosystems [12]. Thirdly, the significantly weak ranking and not-so-close proximity between the "program" and "learn" themes signify some possible disconnection between academic entrepreneurship education and the actual training offered to the learners. In addition, "learn" presented itself to be a fairly weak theme with significantly low ranking, suggesting that UAs could have focused more on improving the authentic learning experiences for students and nascent entrepreneurs, which was emphasised in the literature [1,14]. Fourthly, some intention for generating social and sustainable impacts on the community was interestingly found in the resulting conceptual themes, which corroborates some earlier research [10] that advocated startup development of a more sustainable business model. Nevertheless, the sustainable concept still ranked relatively weak in the concept list (with 10\% relevance), suggesting more could be done to direct the outcome activities toward sustainability. Finally, altogether, given the relatively limited and widespread foci expressed by the investigated UAs, the findings further reinforced our earlier observations, presented as a result of a literature review that stronger emphasis is to be placed by UAs on incorporating entrepreneurial learning [1] and an all-inclusive approach is needed to more deeply integrate UAs into the overall strategic directions and university-bound ecosystem.

\section{Conclusions}

University accelerators are a relatively new phenomenon within broader entrepreneurial ecosystems, the entrepreneurial university, and entrepreneurship education ecosystems. This is the first study, to our knowledge, that explores the UA impact in university strategic intents and practices. The literature on UAs, whilst emerging, recognize its importance to date but has little evidence on the integration of the impact of UAs and alignment of university strategic intent. In addition, there is much disparity regarding the outcomes of 
UAs, with questions asked as to whether such initiatives are startup launchpads or vehicles for entrepreneurial learning. The prominent literature, however, overwhelmingly identifies education as the primary role for accelerator programs. To explore the interface between UAs and the strategic intent of universities, our research identified two main patterns from which we identified two related research gaps.

The first pattern and gap identified disparate points of view regarding the impact and outcomes of UAs, such as disparity between entrepreneurship education imperatives and startup initiatives associated with UAs. The second pattern and gap identified a lack of studies providing evidence of the integration of UA impacts and outcomes with the strategic intents and practices of universities. This, in turn, provided significant incongruence between the substantive and symbolic management outcomes.

In addressing the research question, our findings suggested that the investigated UAs paid most attention to the provision of programs directed at supporting startups and their founders, access to various supporting services and networking events, and connection to the wider community in which entrepreneurs can seek further opportunities to develop skills and expand their impacts. Some interesting observations and interpretations were triggered by our findings. First, we found that there is a significant disparity regarding the impacts and outcomes of UAs. Although there was a consensus on many domains, such as training for early-stage nascent entrepreneurs and provisions for infrastructures for entrepreneurial clusters, there was no sufficient focus on the key elements such as accelerating innovation, crafting sustainable business models, and facilitating high-growth ventures. Despite the global literature identifying entrepreneurship education as the primary role for accelerator programs, this was not evident within the Australian context. Our findings indicate a preference for programs, startup facilitation, mentorships, community/ecosystem engagement, and student/participant access. Second, our Leximancer analyses also highlighted the incongruence between the UA impact and outcomes and university intent and practices. This disconnection is primarily a result of the interplay of substantive and symbolic management practices. The former identified only a few prominent universities active in long-term commitments and the proactivity, innovation, and creativity with regard to UA practices. The latter identified most Australian universities as portraying a lack of commitment and mobilization of UAs.

Despite the disparity of the impacts and outcomes of UAs, these findings provide critical grounding and insights for researchers, practitioners, and university leaders. The limitations to this research are primarily based on the quality and availability of the data on university websites, which were manually screened and collected by the authors, although we mitigated this by engaging and collaborating with many scholars responsible for accelerator programs at universities. Some theoretical and practical implications can be drawn from our research. Theoretically, the findings pave the way for further empirical research to examine the incongruence between the impacts and outcomes of UAs and integration between university strategic intent. Further research is also suggested to examine the disparity between global (predominantly USA and Europe) accelerator impacts and that of Australian accelerators or the impacts of different contexts on UA construction and the implementation of strategic intentions. An overarching question is the role of entrepreneurship education in UAs, further identifying the integration of the startup, engagement, and entrepreneurial learning discussion. Practical implications, particularly relevant to university leaders, managers, and practitioners, include embracing substantive motives to align UAs with the university strategic intent. We propose the inclusion of specific aligned UA items with university strategic intent, such as the startup infrastructure, authentic training, startup facilitation, entrepreneurial learning, innovation acceleration, and entrepreneurship education $[1,12,40]$ via which to make a greater contribution to the development of the overall entrepreneurial ecosystem [41].

Overall, despite the nascent and disparate nature of the UA research and scholarship, the positive impact and outcomes of successful startups in dynamic ecosystems is encouraging. Australian universities can produce even more successful startups by aligning their 
UAs closely with their strategic intent, together with embracing substantive motives to achieve such outcomes.

Author Contributions: A.M. was responsible for scoping this research, the identification of research gaps, and overall research design. Q.N. was responsible for the Leximancer data collection and analyses. H.-M.H. was responsible for the literature review and all researchers for the overall development of the paper, including the introduction and conclusion. All authors have read and agreed to the published version of the manuscript.

Funding: This research received no external funding.

Institutional Review Board Statement: Not Applicable.

Informed Consent Statement: Not applicable.

Data Availability Statement: The data presented in this study are available on request from the corresponding author. The data are not publicly available.

Acknowledgments: We acknowledge the anonymous reviewers and the guest editors of this Special Issue: Entrepreneurship, Competition and Innovation: A Trilogy Research and the editorial team of the Sustainability journal.

Conflicts of Interest: The authors declare no conflict of interest.

\section{References}

1. Metcalf, L.E.; Katona, T.M.; York, J.L. University Startup Accelerators: Startup Launchpads or Vehicles for Entrepreneurial Learning? Entrep. Educ. Pedagog. 2020. [CrossRef]

2. Breznitz, S.M.; Zhang, Q. Fostering the growth of student start-ups from university accelerators: An entrepreneurial ecosystem perspective. Ind. Corp. Chang. 2019, 28, 855-873. [CrossRef]

3. Franco, M. Entrepreneurship, Competitiveness and Innovation. Sustainability 2020, 12, 6576. [CrossRef]

4. Cohen, S.; Fehder, D.C.; Hochberg, Y.V.; Murray, F. The design of startup accelerators. Res. Policy 2019, 48, 1781-1797. [CrossRef]

5. Morris, M.H.; Kuratko, D.F.; Cornwall, J.R. Entrepreneurship Programs and the Modern University; Edward Elgar Publishing: Northhampton, MA, USA, 2013.

6. Szczukiewicz, K.; Makowiec, M. Characteristics and Specificities of Local Innovation Accelerators: A Case of Poland. Sustainability 2021, 13, 1689. [CrossRef]

7. Klofsten, M.; Fayolle, A.; Guerrero, M.; Mian, S.; Urbano, D.; Wright, M. The entrepreneurial university as driver for economic growth and social change-Key strategic challenges. Technol. Forecast. Soc. Chang. 2018, 141, 149-158. [CrossRef]

8. Hathaway, I. What Startup Accelerators Really Do; Harvard Business Review: Boston, MA, USA, 2016.

9. Crișan, E.L.; Salanță, I.I.; Beleiu, I.N.; Bordean, O.N.; Bunduchi, R. A systematic literature review on accelerators. J. Technol. Transf. 2021, 46, 62-89. [CrossRef]

10. Butz, H.; Mrożewski, M.J. The Selection Process and Criteria of Impact Accelerators. An Exploratory Study. Sustainability 2021, 13, 6617. [CrossRef]

11. Bergmann, T.; Utikal, H. How to Support Start-Ups in Developing a Sustainable Business Model: The Case of an European Social Impact Accelerator. Sustainability 2021, 13, 3337. [CrossRef]

12. Maritz, A.; Nguyen, Q.A.; Bliemel, M. Boom or bust? Embedding entrepreneurship in education in Australia. Educ. Train. 2019, 61,737-755. [CrossRef]

13. Bliemel, M.; Flores, R.; De Klerk, S.; Miles, M.P. Accelerators as start-up infrastructure for entrepreneurial clusters. Entrep. Reg. Dev. 2019, 31, 133-149. [CrossRef]

14. Miles, M.P.; de Vries, H.; Harrison, G.; Bliemel, M.; de Klerk, S.; Kasouf, C.J. Accelerators as authentic training experiences for nascent entrepreneurs. Educ. Train. 2017, 59, 811-824. [CrossRef]

15. Nguyen, Q.A.; Maritz, A. Entrepreneurship as a strategic imperative in Australian Universities. In Proceedings of the Australian Centre for Entrepreneurship (ACE) Research Exchange Conference 2019, Brisbane, Australia, 5-8 February 2019 ; pp. 36-37.

16. Overall, J.; Gedeon, S.A.; Valliere, D. What can universities do to promote entrepreneurial intent? An empirical investigation. Int. J. Entrep. Ventur. 2018, 10, 312-332. [CrossRef]

17. Hambrick, D.C.; Lovelace, J.B. The role of executive symbolism in advancing new strategic themes in organizations: A social influence perspective. Acad. Manag. Rev. 2018, 43, 110-131. [CrossRef]

18. Hyatt, D.G.; Berente, N. Substantive or symbolic environmental strategies? Effects of external and internal normative stakeholder pressures. Bus. Strategy Environ. 2017, 26, 1212-1234. [CrossRef]

19. Wurth, B.; Stam, E.; Spigel, B. Toward an entrepreneurial ecosystem research program. Entrep. Theory Pract. 2021. [CrossRef]

20. Belitski, M.; Heron, K. Expanding entrepreneurship education ecosystems. J. Manag. Dev. 2017, 36, 163-177. [CrossRef]

21. Etzkowitz, H. The Entrepreneurial University: Vision and metrics. Ind. High. Educ. 2016, 30, 83-97. [CrossRef] 
22. Jones, C.; Penaluna, K.; Penaluna, A. Value creation in entrepreneurial education: Towards a unified approach. Educ. Train. 2020, 63, 101-113. [CrossRef]

23. Audretsch, D.B.; Belitski, M.; Cherkas, N. Entrepreneurial ecosystems in cities: The role of institutions. PLoS ONE 2021, 16, e0247609. [CrossRef]

24. Spigel, B. The Relational Organization of Entrepreneurial Ecosystems. Entrep. Theory Pract. 2017, 41, 49-72. [CrossRef]

25. Roundy, P.T.; Brockman, B.K.; Bradshaw, M. The resilience of entrepreneurial ecosystems. J. Bus. Ventur. Insights 2017, 8, 99-104. [CrossRef]

26. Shwetzer, C.; Maritz, A.; Nguyen, Q.A. Entrepreneurial ecosystems: A holistic and dynamic approach. J. Ind. Univ. Collab. 2019, 1, 79-95. [CrossRef]

27. Leendertse, J.; Schrijvers, M.; Stam, E. Measure twice, cut once: Entrepreneurial ecosystem metrics. Res. Policy 2021. [CrossRef]

28. Davidsson, P.; Grégoire, D.A.; Lex, M. Venture Idea Assessment (VIA): Development of a needed concept, measure, and research agenda. J. Bus. Ventur. 2021, 36, 106130. [CrossRef]

29. Wadee, A.A.; Padayachee, A. Higher Education: Catalysts for the development of an entrepreneurial ecosystem, or ... are we the weakest link? Sci. Technol. Soc. 2017, 22, 284-309. [CrossRef]

30. Cunningham, J.A.; Menter, M. Transformative change in higher education: Entrepreneurial universities and high-technology entrepreneurship. Ind. Innov. 2021, 28, 343-364. [CrossRef]

31. Battistella, C.; De Toni, A.F.; Pessot, E. Open accelerators for start-ups success: A case study. Eur. J. Innov. Manag. 2017, 20 , 80-111. [CrossRef]

32. Kennett, G.; Hu, L.; Maritz, A.; Sun, H. Learning huddles: Absorptive capacity and sustainable growth of Chinese incubatees. J. Ind.-Univ. Collab. 2020, 2, 141-159. [CrossRef]

33. Emondson, A.; McNamus, S. Methodological fit in management research. Acad. Manag. Rev. 2007, 32, 1155-1179.

34. North, D.C. Institutions, Institutional Change and Economic Performance; Cambridge University Press: Cambridge, UK, 1990.

35. Bruton, G.D.; Ahlstrom, D.; Li, H.L. Institutional theory and entrepreneurship: Where are we now and where do we need to move in the future? Entrep. Theory Pract. 2010, 34, 421-440. [CrossRef]

36. Smith, A.E. Automatic extraction of semantic networks from text using Leximancer. In Proceedings of the HLT-NAACL 2003 Human Language Technology Conference of the North American Chapter of the Association for Computational Linguistics, 27 May-1 June 2003; ACL: Edmonton, AB, Canada, 2003; pp. 23-24. Available online: https://dl.acm.org/doi/abs/10.3115/107342 7.1073439 (accessed on 23 September 2021).

37. Smith, A.E.; Humphreys, M.S. Evaluation of Unsupervised Semantic Mapping of Natural Language with Leximancer Concept Mapping. Behav. Res. Methods 2006, 38, 262-279. [CrossRef] [PubMed]

38. Volery, T.; Mazzarol, T. The Evolution of the Small Business and Entrepreneurship Field: A bibliometric investigation of articles published in the International Small Business Journal. Int. Small Bus. J. 2015, 33, 374-396. [CrossRef]

39. Nguyen, Q.A.; Sullivan Mort, G.; D'Souza, C. Vietnam in Transition: SMEs and the necessitating environment for entrepreneurship development. Entrep. Reg. Dev. 2015, 27, 154-180. [CrossRef]

40. Hausberg, P.; Korreck, S. Business Incubators and Accelerators: Review and Research Agenda; Academy of Management Proceedings: Briarcliff Manor, NY, USA, 2017; p. 17289.

41. Gebczynska, M.; Kwiotkowska, A. Role of accelerators in development of the entrepreneurial ecosystem as a part of the regional economic development strategy. In Proceedings of the IOP Conference Series: Materials Science and Engineering, Kazimierz Dolny, Poland, 21-23 November 2019; p. 102013. 